\title{
Case Management for Immigrant Survivors of Torture: An Examination of HealthRight International's Access to Support and Services for Survivors of Torture Program (ASSIST)
}

\author{
Kelly Barneche $\cdot$ Lisa Matos
}

Published online: 14 March 2014

(C) Springer International Publishing 2014

\begin{abstract}
Objectives This research seeks to determine what impact HealthRight International's Access to Support and Services for Survivors of Torture (ASSIST) remote case management program has on the physical, psychological, and social wellbeing of survivors of torture.

Method A retrospective case record review was conducted of 54 adult foreign-born survivors of torture who received remote case management services through ASSIST. Survivors were interviewed at intake, and 6 months after the initial assessment, the Survivor of Torture Outcomes Matrix (SOT Matrix) was utilized to determine changes in well-being. Results Survivors report improved well-being along with 12 of the 14 indicators in the SOT Matrix between the initial assessment and the 6-month assessment.

Conclusions Findings indicate that survivors report overall improved well-being after 6 months of receiving remote case management, pointing to remote case management as a promising practice which would allow increasing numbers of survivors who live far from traditional torture treatment centers to access specialized care.
\end{abstract}

Keywords Survivor of torture · Immigrant · Case management $\cdot$ Telehealth

\section{Introduction}

The United Nations Universal Declaration of Human Rights states that "No one shall be subjected to torture or to cruel, inhuman or degrading treatment or punishment" (UN General

K. Barneche $(\triangle) \cdot$ L. Matos $(\triangle)$

HealthRight International's Human Rights Clinic, New York, NY,

USA

e-mail: kelly.barneche@healthright.org

e-mail: lisa.matos@healthright.org
Assembly 1948). Nevertheless, throughout the world, people live in fear of abduction, imprisonment, torture, and murder because of their race, religion, nationality, membership in a particular social group, or political opinion. Recognizing such persecution and the frequent need for individuals to flee their homelands, the UN Declaration further proclaims that "everyone has the right to seek and to enjoy in other countries asylum from persecution." The United States government estimates that there are between 400,000 and 500,000 foreign-born survivors of torture living in the USA (United States House of Representatives 2007); a significant number enter without legal status and file for asylum or other forms of legal status once here, seeking stability and safety from further harm.

Although a fleeing survivor may experience an increased sense of safety once in the USA, the physical and psychological effects of past torture can continue to haunt him or her for years. In addition to such symptoms, survivors, particularly those who are seeking asylum, report a host of basic survival needs such as shelter, food, and transportation (Quiroga and Jaranson 2005; Winter 2011). Although primary health care and social services may exist in survivors' communities, asylum seekers and other immigrants who have fled persecution in their home countries are less likely than other immigrant groups to access these services (Asgary and Segar 2011).

In response, organizations around the world have designed torture treatment programs to address the myriad needs of survivors who seek healing, by providing a multidisciplinary approach to treatment that addresses survivors' medical, psychological, social, and legal needs. In the USA, program models vary, with some of the 34 member organizations of the National Consortium of Torture Treatment Programs (NCTTP) across the country offering comprehensive services in-house and others offering a mix of in-house services and referrals. (Quiroga and Jaranson 2005; National Consortium of Torture Treatment Programs 2013). 
In communities where torture treatment centers do not exist, such as areas far from urban centers where treatment centers tend to cluster, or where their capacity might be limited, survivors may find it difficult to access providers who can offer the needed services. Those who do not have legal status, such as asylum seekers, can face even greater challenges, as there is a sense of uncertainty and despair that develops in asylum seekers as they await decisions about their immigration cases (Masocha and Simpson 2011). Raghavan et al. (2012: 6) found that, among predictor variables such as gender, age, marital status, region of birth, employment, and services received, "the strongest correlate of clinical improvement was obtaining legal authorization to remain in the U.S.".

For survivors with legal status, such as refugee survivors, the official status grants them access to assistance from resettlement agencies and government agencies. Asgary and Segar (2011) conducted focus group discussions and comprehensive interviews with 35 asylum seekers and 15 service providers to identify the structural barriers that prevent asylum seekers from accessing health care. The research highlighted the challenges individuals encounter in navigating new and complex social service systems. Challenges like language difficulties and misinformed social service providers can prevent asylum seekers from discovering benefits that might be available to them. As a result, asylum seekers participating in this study requested more involvement from community organizations in navigating these complex systems. Social service professionals such as social workers and case managers, who are trained to refer and connect clients with available services, are well equipped to offer this type of assistance to survivors of torture (Engstrom and Okamura 2004; Winter 2011).

Even if survivors are aware of treatment options and their availability, however, they may still not elect to utilize such services. Moreno et al. (2006) conducted a retrospective chart review to examine healthcare service utilization among the 146 refugees referred to a torture treatment program in Boston. They found that a high percentage of patients declined further services after the initial assessment. Along with scheduling conflicts and lack of transportation, survivors of torture do not access services because of fear of re-traumatization and mistrust of service providers.

Although the effects of torture survivors' trauma history, compounded by the challenges of navigating foreign systems, can render them especially isolated, other populations face challenges in accessing needed services as well. Telehealth and related fields of telepsychiatry and e-health have sought to use the internet and telecommunications technology to reach underserved populations that might not otherwise have access to professional assistance due to geographical isolation or impaired mobility. While research has not yet documented the effects of e-health service provision to survivors of torture in the USA, there is evidence that patients in a variety of settings who received telepsychiatry sessions reported high levels of satisfaction with treatment offered remotely. Patients who preferred telepsychiatry to in-person appointments cited decreases in concerns such as time off work, travel time, and child care arrangements as benefits to the remote appointments (Monnier et al. 2003). For 30 asylum seekers, refugees, and migrants in Denmark and Sweden who accessed telepsychiatry in their own languages, the ability to access care in one's native language without needing to travel was also cited as an advantage of remote treatment (Mucic 2008), allowing for the plausibility of other successful remote interventions with this population that promote access to specialized care.

\section{Access to Support and Services for Survivors of Torture Program}

HealthRight International's New York-based Human Rights Clinic (HRC) was established in 1993 to provide pro bono forensic evaluations for survivors of torture seeking asylum in the USA. Over the past 20 years, HRC has expanded to more than 11 states with high percentages of populations at risk of having been tortured. HRC-trained volunteer clinicians and staff currently serve close to 400 survivors of torture per year, providing exams and affidavits documenting the physical and psychological sequelae of torture in support of survivors' asylum cases.

In 2009, in addition to forensic evaluations, HRC began offering a remote case management program to its clients to help them access medical and psychosocial care in their communities across the country. Approximately $40 \%$ of survivors who receive an evaluation access follow up case management services through HRC's Access to Support and Services for Survivors of Torture (ASSIST) program. Because survivors served through ASSIST are located in various regions of the USA (including AZ, CA, CO, CT, MD, NJ, NY, PA, VA, WA, and Washington, D.C.), the program utilizes a telehealth model for case management. Client needs assessments and referrals are conducted primarily via phone and email rather than in person. ASSIST is staffed by a social worker who supervises a case manager; the case manager is responsible for the vast majority of assessment and referral activities.

For this study, the authors sought to determine what impact, if any, ASSIST case management services had on the physical, psychological, and social well-being of survivors of torture seeking to stabilize immigration status. It was hypothesized that survivors who received ASSIST case management would demonstrate improved well-being 6 months after initial assessment in at least 1 of the 14 measured indicators. 


\section{Method}

Participants

A retrospective case record review was conducted of 54 adult foreign-born survivors of torture who received an initial assessment, case management services, and a 6-month assessment through ASSIST, between June 2012 and November 2013. This represents $72 \%$ of the total number of clients who were referred to ASSIST for case management; the remaining $28 \%$ either did not elect to receive case management or received case management but lost contact with ASSIST staff and, as a result, did not receive a 6-month assessment. The average age of participants was 35 years old, and $51.9 \%$ identified as women, $44.4 \%$ as men, and $3.7 \%$ as transgender. They came from a wide variety of countries: the Gambia (6), Ethiopia (5), Kenya (4), Mexico (4), Democratic Republic of the Congo (3), El Salvador (2), Honduras (2), Nepal (2), Russia (2), Uganda (2), Albania (1), Angola (1), Bangladesh (1), Bosnia, Herzegovina (1), Brazil (1), Chad (1), Djibouti (1), Egypt (1), Fiji (1), Ghana (1), Kosovo (1), Mali (1), Mauritania (1), Nigeria (1), Peru (1), Rwanda (1), Sierra Leone (1), Sri Lanka (1), Sudan (1), Togo (1), Trinidad and Tobago (1), and Zimbabwe (1). Twenty-two participants lived in New York State, and the remainder lived in Washington State (19), Colorado (7), California (2), New Jersey (2) Connecticut (1), and Maine (1).

\section{Procedures}

All study participants received at least one pro bono medical, gynecological, or psychological evaluation from an HRCtrained volunteer clinician to document the sequelae of torture and abuse they suffered. After the evaluation, the clinician conducted a brief needs assessment and offered the participant the opportunity to request case management from ASSIST. Clients who wished to do so then signed a consent form, and information about the services they requested was sent to the ASSIST social worker, who screened requests and shared them with the case manager. The case manager then contacted the client by phone to conduct an initial assessment of client needs. Based on the services the client requested, the case manager made referrals to medical, mental health, and social service providers in the client's community. In total, participants were referred for 575 services during their initial 6 months in the ASSIST program, an average of around 10 services per participant.

Provider organizations ranged from more specialized torture treatment centers to community-based organizations such as food pantries and shelters. The case manager maintained contact with the clients after making referrals, troubleshooting, or making additional referrals as needed. Six months after the initial assessment, the case manager contacted the client for a follow-up assessment applying the same procedure as employed in the first assessment.

\section{Measures}

The Survivor of Torture Outcomes Matrix (SOT Matrix) was utilized for each initial (T1) and 6 months (T2) assessment. The SOT Matrix, created by ASSIST staff, is an adaptation of the Self-Sufficiency Matrix, designed for use with individuals moving out of poverty by the Self-Sufficiency Task Force of Snohomish County and based on the federal outcomes standard Results-Oriented Management and Accountability (Snohomish County Self-Sufficiency Task Force 2004). The Self-Sufficiency Matrix demonstrates good reliability, with internal reliability of client dysfunction $=0.79$, independent life skills $=0.78$, and overall self-sufficiency $=0.81$ (Culhane et al. 2007). It has already been adapted for youth aging out of foster care and survivors of trafficking (Senteio et al. 2009; Coalition to Abolish Slavery and Trafficking 2002). ASSIST staff made adjustments to the tool to more accurately capture the circumstances that foreign-born survivors of torture face in the USA. A program evaluation consultant was funded by a national capacity building project grant for torture treatment service providers, assisted with the instrument adaptation process.

The SOT Matrix serves a dual function as a case management tool, guiding the case manager's assessment of the client, and as a program evaluation tool used for monitoring and evaluating service provision. It is comprised 14 different indicators: medical/physical symptoms, medical services access, mental health symptoms, mental health care access, medical insurance, food, clothing, housing, close relations, employment, income, English ability and literacy skills, community involvement, and legal needs. During the initial phone interview, the case manager conducts a semi-structured interview utilizing the SOT Matrix. Based on the responses, the case manager ranks the client on a Likert scale from 1 (very poor) to 4 (very good) for each indicator. The four possible scores per indicator are explained in further detail on the SOT Matrix; for instance, in the medical/physical symptoms category, 1 indicates "symptoms are disabling" and 4 indicates "symptoms not present." SOT Matrix scores then become a part of the client's case record and contribute to an overall program evaluation database.

\section{Results}

A frequency table was generated to examine the number of participants who were scored $1-4$ on each indicator. Table 1 shows the changes in numbers of participants who scored on the first indicator "medical/physical symptoms" between the initial and 6-month assessments. Sixteen more clients reported 
Table 1 Initial (T1) and 6-month (T2) survivor of torture outcomes matrix assessment results for medical/physical symptoms (indicator no. 1)

\begin{tabular}{llll}
\hline Scores for medical/physical symptoms & T1 $n=54$ & T2 $n=54$ & Percent change \\
\hline 4. Symptoms not present & $15(28 \%)$ & $31(57 \%)$ & +1.07 \\
3. Symptoms present but not difficult or disruptive & $24(44 \%)$ & $14(26 \%)$ & -0.42 \\
2. Symptoms not disabling but are difficult & $15(28 \%)$ & $9(17 \%)$ & -0.40 \\
1. Symptoms are disabling & 0 & 0 & 0 \\
\hline
\end{tabular}

that physical symptoms were not present at T2 than did at T1, indicating symptom improvement over 6 months.

A two-tailed paired samples $t$ test was used to analyze the relationship between participants' scores at T1 and T2 on each of the 14 indicators. Table 2 shows the changes from the initial screening to the 6-month screening. On 12 of the indicators, participants demonstrated improved well-being (with a $p$ value equal to or below 0.05 ) at T2 as compared with T1. The two indicators on which participants did not demonstrate statistically significant improvement after 6 months were "English ability and literacy skills" and "community involvement." The two areas of greatest change in score were "medical insurance" (T1 average 1.6, $\mathrm{SD}=0.82$, T2 average 2.4, $\mathrm{SD}=1.16$ ), with a $54 \%$ increase and "mental health care access" (T1 average $1.7, \mathrm{SD}=0.9, \mathrm{~T} 2$ average $2.3, \mathrm{SD}=$ $1.19)$ with a $38 \%$ increase.

Thirteen participants reported that they had been granted asylum by the 6-month assessment while the rest were still awaiting their outcomes. To compare 6-month scores for clients who were and who were not granted legal status, a two-samples, two-tailed $t$ test was utilized (Table 3 ). Those with legal status at the 6-month assessment reported significantly higher scores as compared with their counterparts who had not yet been granted status on seven indicators: medical/ physical symptoms, medical insurance, food, clothing, employment, income, and legal needs. Participants with legal status by their 6-month assessment did not report significantly better mental health than did those without status at the 6month assessment. Other indicators not significantly affected by grant of legal status were mental health symptoms, medical access, mental health care access, housing, close relations, English ability and literacy, and community involvement.

\section{Discussion}

Findings indicate that ASSIST clients report improved overall well-being after 6 months of receiving remote case management. The two indicators on which clients demonstrated the most improvement between T1 and T2 were "(access to) medical insurance" and "mental health care access", possibly indicating the effectiveness of case management referrals for both. This could also be a function of the fact that several participants were granted asylum before the 6-month evaluation, and, once granted asylum, survivors are eligible for Medicaid.
One area in which clients with and without legal status did not report significant improvement was in "English ability and literacy skills." The ASSIST case manager made ESL class referrals for clients who requested such information; in cases where a client with little English-speaking ability elected to not receive ESL class information, he or she often cited more pressing challenges, such as lack of access to food or warm clothing, priorities at that time. It is also possible that four ranking choices are too few to effectively measure growth in English skills and literacy in only 6 months, given that the options range from "no English-speaking ability" to "easily conversational in English." Effectively monitoring survivors' progress in English skills, therefore, could require a longer follow-up period than 6 months or more than four categories.

Another area in which participants did not demonstrate significant improvement was "community involvement." Because the SOT Matrix is based on client answers to interview questions, there is room for multiple interpretations of what constitutes "community involvement." In fact, whereas some survivors may wish to be involved with immigrants from their home countries, others may avoid doing so for fear of encountering individuals representing opposite sides of a conflict from which they fled (Chambon et al. 2001). For this reason, questions about community involvement were framed in terms of how connected or isolated a participant felt from people in the community; however, he or she defined the term.

Whereas case management referrals did directly address English skills or other indicators such as access to medical care or food, they did not directly address a client's level of community involvement. This is because referrals typically focus on a client's concrete expressed need, and they are made for traditional social service providers such as clinics and food pantries rather than for more explicitly social activities or opportunities. It is also possible that this represents a limitation of the remote case management model: since clients do not visit a brick-and-mortar facility for case management and activities, they are not able to establish a relationship with a service provider or fellow clients in his or her own community. How a remote case management model such as ASSIST might better help clients address issues of community involvement warrants further exploration, as levels of social isolation tend to be high among asylum seekers, and repairing a ruptured ability to trust others is a key element in a survivor's path to healing (McColl and Johnson 2006; Fabri 2001; Chambon et al. 2001). 
Table 2 Average assessment scores per indicator on a fourpoint scale $(N=54)$
$* p \leq 0.05$

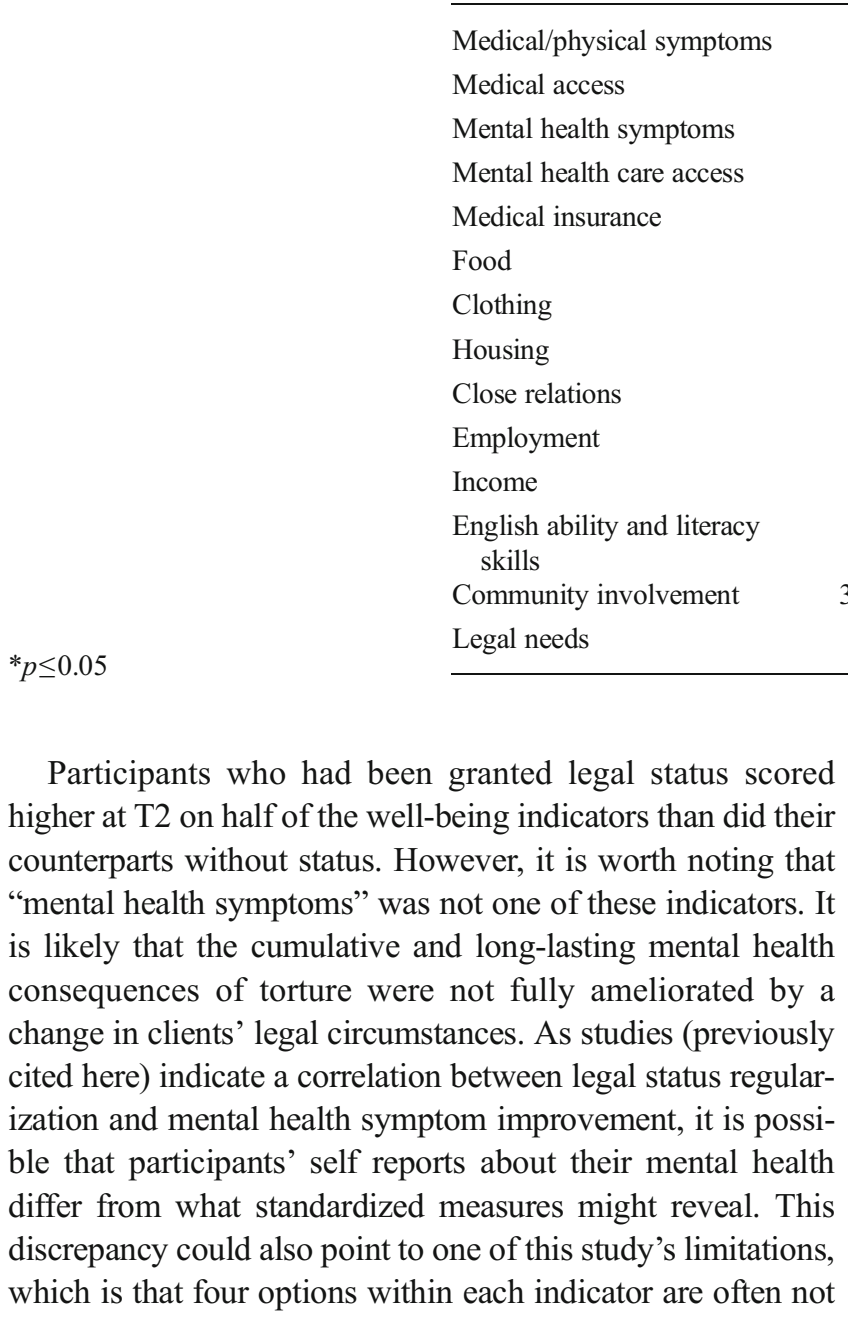

\begin{tabular}{lccc}
\hline Indicator & $\begin{array}{l}\text { Initial T1 average (SD) } \\
\text { score }\end{array}$ & $\begin{array}{l}\text { 6-month T2 average (SD) } \\
\text { score }\end{array}$ & $\begin{array}{l}\text { Percent } \\
\text { change }\end{array}$ \\
\hline Medical/physical symptoms & $3.0(0.75)$ & $3.4(0.77)$ & $0.14^{*}$ \\
Medical access & $2.5(0.98)$ & $3.1(0.87)$ & $0.23^{*}$ \\
Mental health symptoms & $2.6(0.74)$ & $3.2(0.83)$ & $0.24^{*}$ \\
Mental health care access & $1.7(0.9)$ & $2.3(1.19)$ & $0.38^{*}$ \\
Medical insurance & $1.6(0.82)$ & $2.4(1.16)$ & $0.54^{*}$ \\
Food & $2.7(0.81)$ & $3.1(0.9)$ & $0.14^{*}$ \\
Clothing & $2.8(0.93)$ & $3.2(0.96)$ & $0.14^{*}$ \\
Housing & $2.9(0.82)$ & $3.4(0.71)$ & $0.15^{*}$ \\
Close relations & $2.6(0.81)$ & $3.1(0.83)$ & $0.18^{*}$ \\
Employment & $2.0(1.09)$ & $2.6(1.14)$ & $0.30^{*}$ \\
Income & $2.2(1.08)$ & $2.7(1.07)$ & $0.25^{*}$ \\
English ability and literacy & $3.2(0.92)$ & $3.4(0.79)$ & 0.075 \\
$\quad$ skills & $3.06(0.74)$ & $3.09(0.71)$ & 0.01 \\
Community involvement & $3.0(0.27)$ & $3.3(0.43)$ & $0.08^{*}$ \\
Legal needs & & & \\
\hline
\end{tabular}

Table 3 Variations in average 6month assessment (T2) scores of ASSIST clients based on legal status sufficient to accurately capture the nuances of an individual client's situation, particularly with regard to mental health well-being, which may change from day to day. It is also possible that a 6-month period of time is too short to adequately capture improvement in mental health symptoms among survivors, especially when some might have been granted legal status shortly before the second assessment took place. Connecting clients to culturally appropriate and affordable mental health care remains a challenge for ASSIST staff, and this finding highlights the importance of continued efforts to improve client access to effective treatment.

Additional study limitations include the relatively small sample size of 54 participants, the lack of a control group for

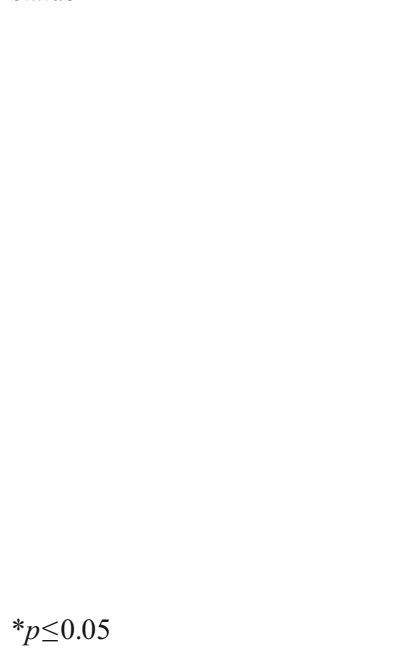

\begin{tabular}{lll}
\hline Indicator & $\begin{array}{l}\text { Clients without legal status } \\
n=41(\mathrm{SD})\end{array}$ & $\begin{array}{l}\text { Clients with legal status } \\
n=13(\mathrm{SD})\end{array}$ \\
\hline Medical/physical symptoms* & $3.3(0.78)$ & $3.8(0.60)$ \\
Medical access & $3.0(0.92)$ & $3.2(0.73)$ \\
Mental health symptoms & $3.1(0.83)$ & $3.3(0.85)$ \\
Mental health care access & $2.3(1.19)$ & $2.4(1.26)$ \\
Medical insurance* & $2.3(1.17)$ & $3.0(0.91)$ \\
Food* & $3.0(0.95)$ & $3.6(0.51)$ \\
Clothing* & $3.0(1.01)$ & $3.8(0.38)$ \\
Housing & $3.3(0.72)$ & $3.5(0.66)$ \\
Close Relations & $3.0(0.86)$ & $3.2(0.73)$ \\
Employment* & $2.4(1.13)$ & $3.3(0.95)$ \\
Income* & $2.5(1.09)$ & $3.5(0.66)$ \\
English ability and literacy skills & $3.4(0.83)$ & $3.6(0.65)$ \\
Community involvement & $3.0(0.73)$ & $3.3(0.63)$ \\
Legal needs* & $3.0(0.33)$ & $4.0(0)$ \\
\hline
\end{tabular}


comparison, the use of an adapted measurement instrument, and the subjective nature of basing scores on case manager assessments rather than strictly on client self-reporting, which due to bias or misunderstanding can result in SOT Matrix scores inaccurately reflecting client well-being. Selection bias may have influenced findings, as the clients included in this study were those who responded to case manager calls, indicating their access to a telephone and a desire to be in contact with a service provider. Because this research was conducted retrospectively from case management records, it was neither possible nor ethical to withhold treatment from clients for the sake of creating a comparison group. The lack of a comparison group and the use of a measurement instrument that has not been validated outside of the agency setting are common features of research conducted with survivors of torture (Jaranson and Quiroga 2011).

As few case management outcome studies and related instruments currently exist in the field of torture treatment, the use of the Survivor of Torture Outcomes Matrix as a valid tool for assessing changes in survivor well-being merits further investigation. The addition of a 9 or 12-month assessment to the current protocol would yield additional information and measure the more lasting impact of case management services, especially in areas where a 6-month period might be too short to adequately capture improvement, such as "English ability and literacy skills" and "community involvement," or even "mental health symptoms."

The major strength of this research is that it offers insight into the impact that remote case management can have on survivors' well-being, as measured by an instrument adapted specifically for the use with this population. Results indicate that ASSIST clients experience overall improved well-being after 6 months of receiving remote case management, pointing to the remote model as a promising practice which would allow increasing numbers of survivors who live far from service providers to access specialized care; the remote model could also be used by traditional brick-and-mortar treatment centers to serve clients who are geographically isolated and to begin building safe, happy, and hopeful lives in the USA.

Acknowledgments The authors wish to thank Isabel Barbosa, Meryl Hulse, Kanhong Lin, Martina Lanfranchi, Sacha Christianson, and Isabel Morales for their assistance with this project.

\section{References}

Asgary, R., \& Segar, N. (2011). Barriers to health care access among refugee asylum seekers. Journal of Health Care for the Poor and Underserved, 22, 506-522.

Chambon, McGrath, Shapiro, Abai, \& Dudziak. (2001). From interpersonal links to webs of relations: creating befriending relationships with survivors of torture and war. Journal of Social Work Research, 2(2), 157-171.
Coalition to Abolish Slavery and Trafficking (2002). [CD-ROM]. CAST client assessment/outcome matrix. The Salvation Army Anti-Trafficking Training Manual (2nd Ed.).

Culhane, D. P., Parker, W. D., Poppe, B., Gross, K. S., \& Sykes, E. (2007, March). Accountability, cost-effectiveness, and program performance: progress since 1998. In National Symposium on Homelessness Research. Symposium conducted by Abt Associates Inc. and Policy Research Associates Inc. under contract for the Office of the Assistant Secretary for Planning and Evaluation, U.S. Department of Health and Human Services; and the Office of Policy.

Development and Research, U.S. Department of Housing and Urban Development. Retrieved from http://aspe.hhs.gov/hsp/ homelessness/symposium07/culhane/report.pdf.

Engstrom, D. W., \& Okamura, A. (2004). Working with survivors of torture: approaches to helping. Families in Society: The Journal of Contemporary Social Services, 85(3), 301-309.

Fabri, M. R. (2001). Reconstructing safety: adjustments to the therapeutic frame in the treatment of survivors of political torture. Professional Psychology Research and Practice, 32(5), 452-457. doi:10.1037/ 0735-7028.32.5.452.

Jaranson, J. M., \& Quiroga, J. (2011). Evaluating the services of torture rehabilitation programmes: history and recommendations. Torture, 21(2), 98-140.

Masocha, S., \& Simpson, M. K. (2011). Developing mental health social work for asylum seekers: a proposed model for practice. Journal of Social Work, 12(4), 424-442. doi:10.1177/1468017310392283.

McColl, H., \& Johnson, S. (2006). Characteristics and needs of asylum seekers and refugees in contact with London community mental health teams. Social Psychiatry and Psychiatric Epidemiology, 41(10), 789-795. doi:10.1007/s00127-006-01012-y.

Monnier, J., Knapp, R. G., \& Frueh, B. C. (2003). Recent advances in telepsychiatry: an updated review. Psychiatric Services, 54(12), 1604-1609.

Moreno, A., Piwowarczyk, L., LaMorte, W. W., \& Grodin, M. A. (2006). Characteristics and utilization of primary care services in a torture rehabilitation center. Journal of Immigrant and Minority Health, 8(2), 163-171. doi:10.1007/s10903-006-8524-x.

Mucic, D. (2008). International telepsychiatry: a study of patient acceptability. Journal of Telemedicine and Telecare, 14, 241-243. doi:10. 1258/jyy.2008.080301.

National Consortium of Torture Treatment Programs (2013). Retrieved 13 December 2013 from http://www.ncttp.org/index.html.

Quiroga, J., \& Jaranson, J. M. (2005). Politically motivated torture and its survivors: a desk study review of the literature. Torture, 16(2-3), 1-96.

Raghavan, S., Rasmussen, A., Rosenfeld, B., \& Keller, A. S. (2012). Correlates of symptom reduction in treatment-seeking survivors of torture. Psychological Trauma: Theory, Research, Practice and Policy, 30, 1-7. doi:10.1037/a0028118.

Senteio, C., Marshall, K. J., Ritzen, E. K., \& Grant, J. (2009). Preventing homelessness: an examination of the transition resource action center. Journal of Prevention \& Intervention in the Community, 37(2), 100-111.

Snohomish County Self-Sufficiency Task Force. (2004). Self-sufficiency matrix. Retrieved 13 December 2013 from http://www.performwell. org/index.php/find-surveyassessments/outcomes/employment-ahousing/housing-and-shelter/self-sufficiency-matrix-an-assessmentand-measurement-tool-created-through-a-collaborative-partnershipof-the-human-services-community-in-snohomish-county.

UN General Assembly (1948, December 10). Universal declaration of human rights. Retrieved 13 December 2013 from http://www. refworld.org/docid/3ae6b3712c.html.

United States. House of Representatives (2007, April 20). Torture victims reauthorization act of 2007. Retrieved 13 Dec 2013 from http://www. gpo.gov/fdsys/pkg/CRPT-110hrpt103/html/CRPT-110hrpt103-pt1.htm.

Winter, A. M. (2011). Social services: effective practices in serving survivors of torture. Torture, 21(1), 49-55. 